Bentham open
CrossMark
Content list available at: www.benthamopen.com/TOCIEJ/
DOI: $10.2174 / 1874149501711010873$

RESEARCH ARTICLE

\title{
Fastener Scaffold Stability Analysis and Experimental Research Under Non-Uniform Distributed Load
}

\author{
Dong Chen ${ }^{1, *}$, Yuzhuo $\mathrm{Wang}^{2}$ and Xiping $\mathrm{He}^{1}$ \\ ${ }^{I}$ School of Civil Engineering, Anhui Jianzhu University, Hefei, 230601, China \\ ${ }^{2}$ School of Civil Engineering, Shandong Jianzhu University, Jinan, 250101, China
}

Received: January 20, 2017

Revised: April 5, 2017

Accepted: May 1, 2017

\begin{abstract}
:
Introduction:

An experiment was carried out on the basis of material nonlinearity, geometry nonlinearity and semi rigid fasteners for the internal force distribution and transfer rules of the scaffold.
\end{abstract}

\section{Methods:}

This paper presents results from a set of numerical studies on the influence of the random imperfection method, the interaction of various imperfections and the most disadvantageous stability limit load.

\section{Result and Conclusion:}

Data from numerical studies indicate that stress at the top of the vertical bar was larger within the scope of load; and the horizontal bar and brace participated in the work of the scaffold. The internal force that came through the two types of bars enabled us to realize the redistribution in every vertical bar in order to decrease the stress from the top to the bottom of the vertical bars and involve them in the work of the scaffold. Data from numerical studies also indicates that these imperfections all interact with each other and the load distribution also influences the scaffold's stability.

Keywords: Fastener scaffold, Non-uniform distributed load, Consistent imperfection method, Stability analysis, Semi-rigid, Urbanization strategies.

\section{INTRODUCTION}

A fastener scaffold is a type of supporting system with convenient installation and easy transportation. With the increase of Chinese urbanization strategies, the use of this type of scaffold has increased dramatically; however, its collapse also occurs frequently during the construction stage. Scaffold collapse accidents belong to the major hazards to the project builders [1], so this accident should carry great importance.

A fastener scaffold is a framed structure sensitive to imperfections as a result of deformation, wear and the corrosion of steel tubes and fasteners [2]. There are currently many studies regarding its stability, both in China and abroad, but most of the achievements have focused on the influence of shelf stability regarding semi-rigid fasteners and the space between steel tubes [3 - 5]. There were fewer studies on imperfect scaffold stability, and they focused largely on uniform distributed loads and the single imperfection effects on the stability of the frame [6-8]. There are fewer studies that examine the scaffold with the interaction of various imperfections under non-uniform distributed loads.

\footnotetext{
* Address correspondence to this author at College of Civil Engineering, Anhui Jianzhu University, Ziyun road 292\#, Hefei economic and Technological Development Zone, Hefei, 230601, China; Tel: +8615256982316; E-mail: chenchenchu@163.com
} 
Fastener scaffold imperfections include early bending, differing diameters and steel tube thickness, fastener tightening torque and the erection deviation. These imperfections are randomly distributed in actual applications [9].

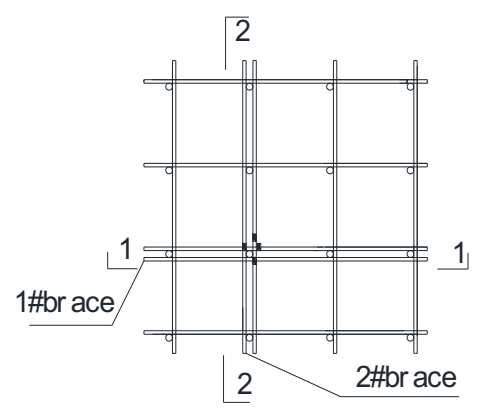

a. Scaffold plane figure

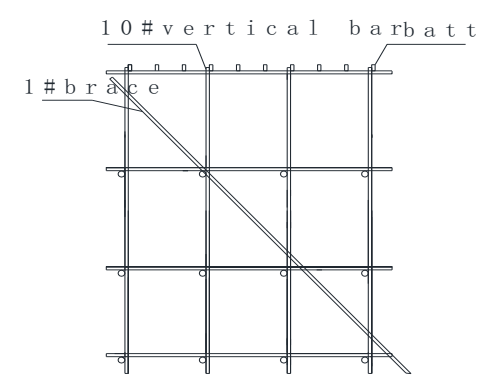

b. 1-1 Profile figure

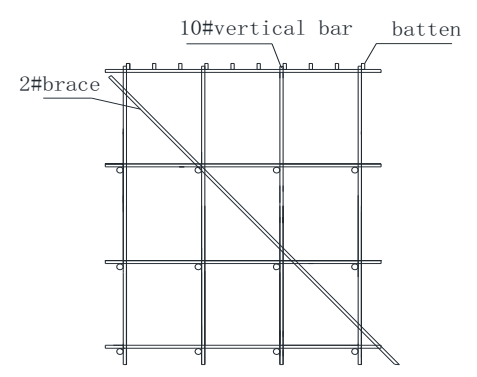

c. 2-2 Profile figure

Fig. (1). Scaffold erection figure.

Therefore, according to the above scenarios, the following research was performed.

1. An experiment was developed to examine fastener scaffolds under non-uniform distributed loads; the internal force transmission and the distribution rules about scaffold were studied and the finite element software ANSYS was used to simulate the experiment.

2. According to the specifications [10], using ANSYS, we established an $8 \times 8 \times 6$ full hall scaffold; the internal force transmission and distribution rules for the scaffold were studied under different non-uniform distributed loads.

3. The scaffold stability of three different erection deviations was studied using the Monte Carlo random sampling 
method (i.e. random imperfection method); the most unfavorable erection deviation form was found.

4. On the basis of the above research, using the consistent imperfection method combined with the actual sizes and various interacting imperfections, the stable limit load was analyzed, and using the random imperfection method, the reliability of this load for minimum stable limit load was found.

\section{SCAFFOLD EXPERIMENT}

\subsection{Experiment Program}

\subsubsection{Scaffold Build-up Program:}

The scaffold build-up form is as shown in Fig. (1). The total size was $2850 \mathrm{~mm} \times 2850 \mathrm{~mm} \times 4000 \mathrm{~mm}$; The space between the vertical bars was $950 \mathrm{~mm}$; the space between the horizontal bars was $1300 \mathrm{~mm}$; the braces were set on both directions of the scaffold, and the horizontal space between the bottom bar and the ground was $100 \mathrm{~mm}$.

The scaffold was made up of 50 steel tubes; the measurement of the outside diameter of an average steel tube was $\mathrm{R}=24.159 \mathrm{~mm}$ and the inner diameter average was $\mathrm{r}=20.855 \mathrm{~mm}$; the yield strength average was $f_{y}=235 \mathrm{MPa}$, the Poisson ratio was $\mu=0.3$. All fasteners used torque wrench fastening with a tightening torque of $40 \mathrm{~N} \cdot \mathrm{m}$.

\subsection{Testing Load}

\subsubsection{Loading Equipment:}

In order to achieve the non-uniform distributed load, the test load was performed as shown in Fig. (2). Methods of force transmission: hydraulic jack $\rightarrow$ flanged beam $\rightarrow$ steel plate $\rightarrow$ wood template $\rightarrow$ batten $\rightarrow$ horizontal bar, and hydraulic jack were located in the loading surface center of the scaffold.

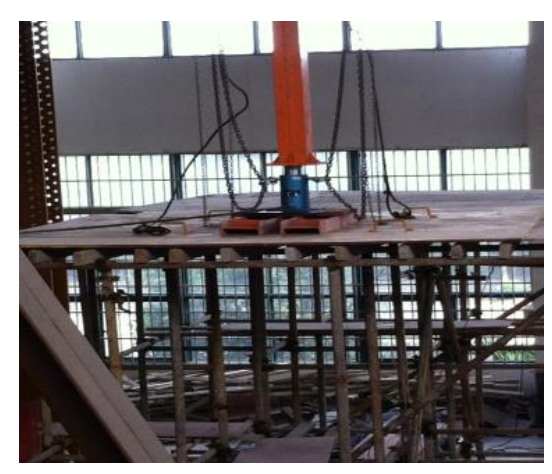

Fig. (2). Loading Equipment.

\subsubsection{Loading Program:}

The loading program for the test is shown in Table $\mathbf{1}$.

Table 1. Loading series and loading value.

\begin{tabular}{|c|l|l|}
\hline Serial Number & $\begin{array}{l}\text { Each Stage Load } \\
(\mathbf{K N})\end{array}$ & \multicolumn{1}{l|}{ Cumulative Load By Jack(KN) } \\
\hline 1 & 8.732 & 8.732 \\
\hline 2 & 4.061 & 20.793 \\
\hline 3 & 8.123 & 29.039 \\
\hline 4 & 8.123 & 37.162 \\
\hline 5 & 8.123 & 45.285 \\
\hline 6 & 8.123 & 53.408 \\
\hline 7 & 8.123 & 61.531 \\
\hline 8 & 8.123 & 69.654 \\
\hline 9 & 8.123 & 77.777 \\
\hline 10 & 8.123 & \\
\hline
\end{tabular}


(Table $\square$ ) contd.....

Table $\square$ contd.....
\begin{tabular}{|c|l|c|}
\hline Serial Number & $\begin{array}{l}\text { Each Stage Load } \\
(\text { KN) }\end{array}$ & Cumulative Load By Jack(KN) \\
\hline 11 & 8.123 & 85.9 \\
\hline 12 & 8.123 & 94.023 \\
\hline 13 & 8.123 & 102.146 \\
\hline 14 & 8.123 & 110.269 \\
\hline 15 & 8.123 & 118.392 \\
\hline 16 & 8.123 & 126.515 \\
\hline 17 & 8.123 & 134.638 \\
\hline
\end{tabular}

The test steps were divided into a preload step and a formal load step. The aim of the preload was to determine whether the measuring instrument would work normally. After the preload the formal load commenced. The load was divided into several levels and every level was sustained $15 \mathrm{~min}$ in order to maintain the scaffold's mechanical stability.

\subsection{Measuring Equipment and Arrangement of Measuring Points}

\subsubsection{Measuring equipment:}

The experiment's method of stress measurement used a distributed optical fiber (BOTDA) system in order to accurately find the data for force transmission and distribution. The instruments were ordinary single mode optical fibers and an optical fiber data acquisition device, as shown in Fig. (3). Using this equipment, we obtained the data for the area covered by optical fibers. The displacement measurement of the scaffold used the HYD-200 displacement meter.
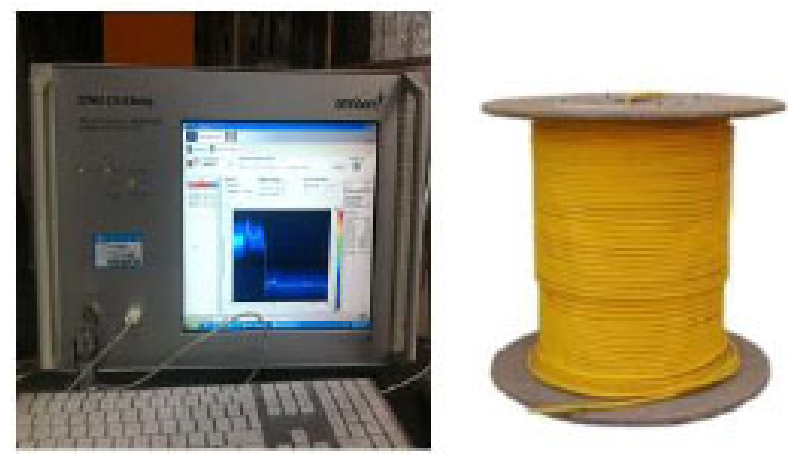

Fig. (3). Distributed optical fiber system.

Optical fiber laying and monitoring point arrangement: Optical fiber lying as shown in Figs. (4 and 5).

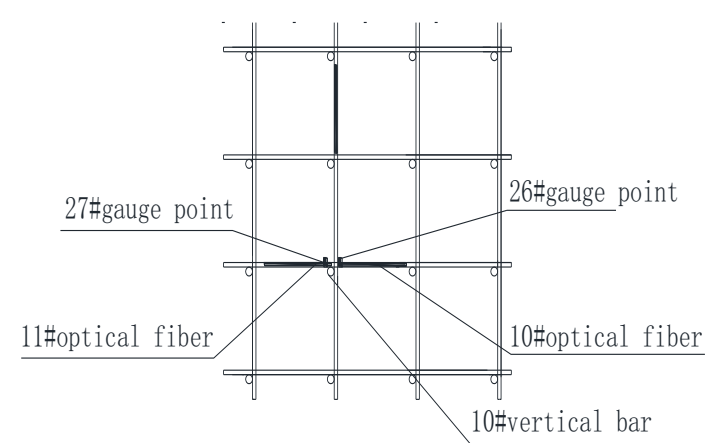

Fig. (4). Fiber lying on the third layer. 


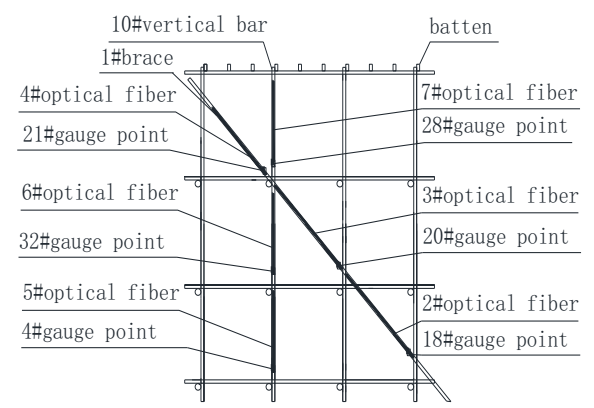

Fig. (5). Fiber laying on profile.

The displacement meter was placed on top of the 10th vertical bar in the third layer. Arrangement is shown in Fig. (6).

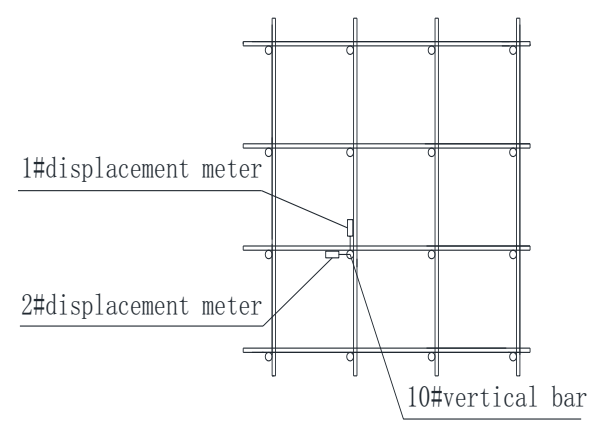

Fig. (6). Displacement meter arrangement.

\subsection{Fasteners Torsion Test}

In essence, the fastener is a type of semi-rigid connection [8]. Therefore, it was important that we confirmed its $\mathrm{M}$ vs $\theta$. relation curve. The test for the fastener with torsion $40 \mathrm{~N} \cdot \mathrm{m}$ was performed, using a hydraulic universal testing machine to fix the vertical bar and a hydraulic jack to load the horizon bar. Every load step was $0.1 \mathrm{KN}$. The displacement meter was placed on the horizon and vertical bars, as shown in Figs. (7 and 8) where $\mathrm{L}=1000 \mathrm{~mm}$, $\mathrm{La}=\mathrm{Lb}=200 \mathrm{~mm}$. In this paper, four groups of tests were carried out; the average test data can be found in Table 2.

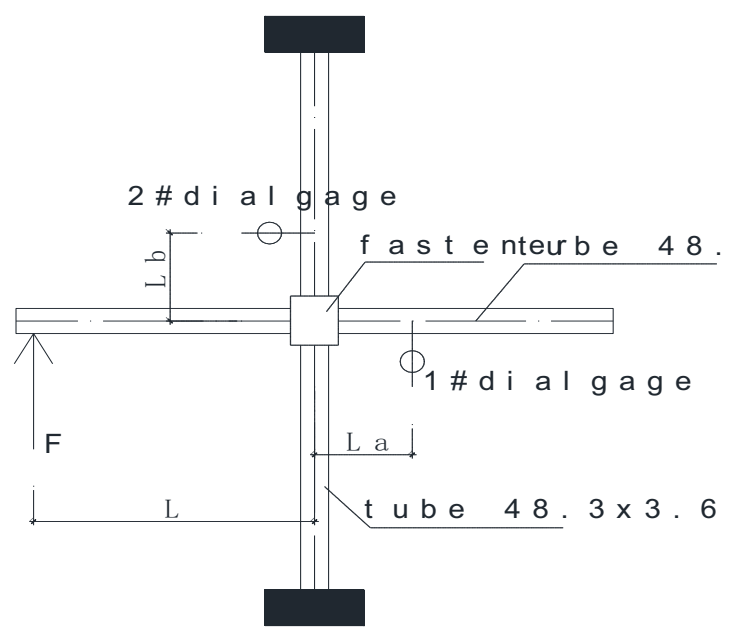

Fig. (7). Fastener torsion test schematic diagram. 


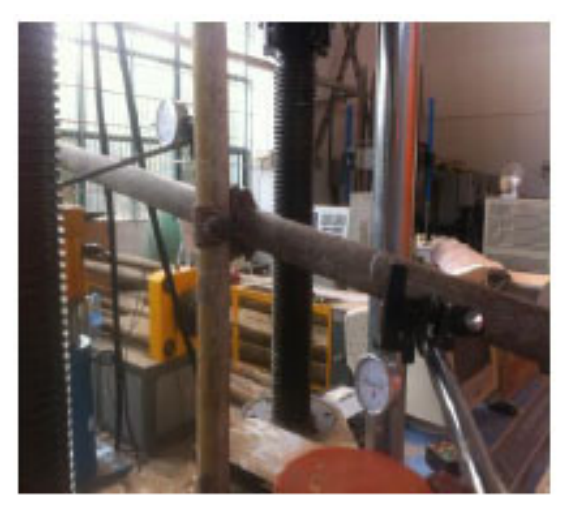

Fig. (8). Fastener torsion test site map.

Table 2. Fastener torsion test data.

\begin{tabular}{|c|c|c|c|}
\hline Fastener Tightening Torque Values 40N·m & Sa(mm) & $\mathbf{\theta}(\mathbf{r a d})$ \\
\hline Bending Moment(kN·m) & 1.370 & 0.732 & 0.003 \\
\hline 0.1 & 2.297 & 0.874 & 0.007 \\
\hline 0.2 & 2.988 & 1.011 & 0.010 \\
\hline 0.3 & 4.147 & 1.246 & 0.015 \\
\hline 0.4 & 6.106 & 1.484 & 0.023 \\
\hline 0.5 & 7.797 & 1.592 & 0.031 \\
\hline 0.6 & 10.297 & 1.632 & 0.043 \\
\hline 0.7 & 15.297 & 1.832 & 0.067 \\
\hline 0.8 & 21.297 & 2.732 & 0.093 \\
\hline 0.90 & & & \\
\hline
\end{tabular}

\subsection{Experimental Result and Simulation Analysis}

\subsubsection{Experimental Results:}

As seen in Fig. (9), we found a rough linear relation curve of load vs. the stress on the upper, middle, and lower parts of 10th vertical bar. The stress decreased from the top to the bottom of the 10th vertical bar. The reason for this phenomenon was that the horizontal bars and the brace transferred force in the 10th vertical bar to the other vertical bars to result in a stress decrease from top to bottom in 10 th vertical bar.

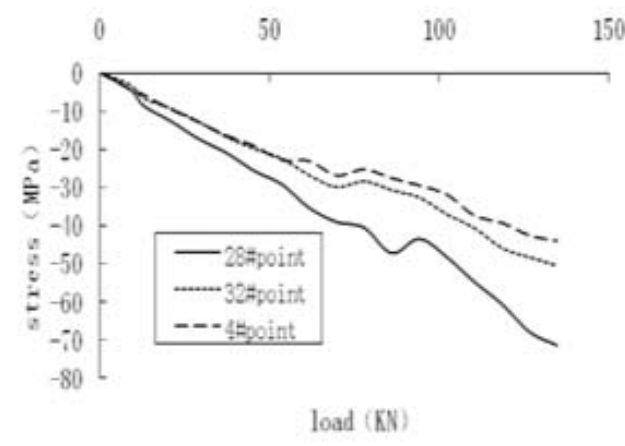

Fig. (9). Stress vs. load diagram on different parts of 10 vertical bars.

The 26 gauge point and the 27 gauge point belonged to the same horizontal bar but were located on opposite sides of 10th vertical bar, as shown Fig. (4). Given Fig. (10), we can see the relationship between stress and external load was a somewhat linear one. Meanwhile, the stress was roughly equal to the size, but in the opposite direction. This was due to bending deformation caused by the force on the 10th vertical bar. 


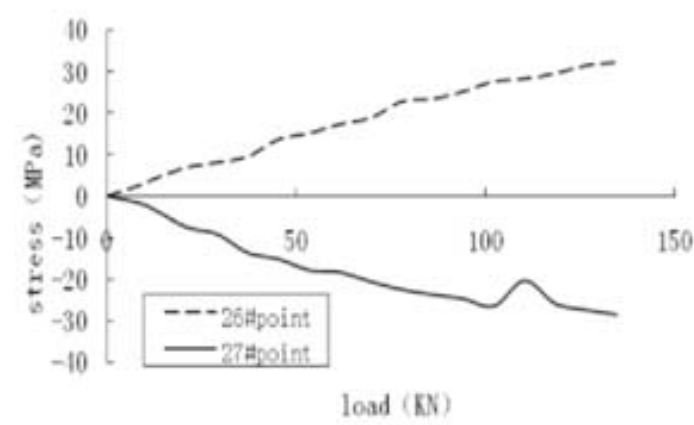

Fig. (10). Stress vs. load diagram of horizontal tube.

As seen in Fig. (11), the relationship between the stress of the brace and the external load was roughly linear, and the stress on the top, middle, and bottom of the brace were approximately equal. Therefore, it was feasible that the brace was the axial force bar.

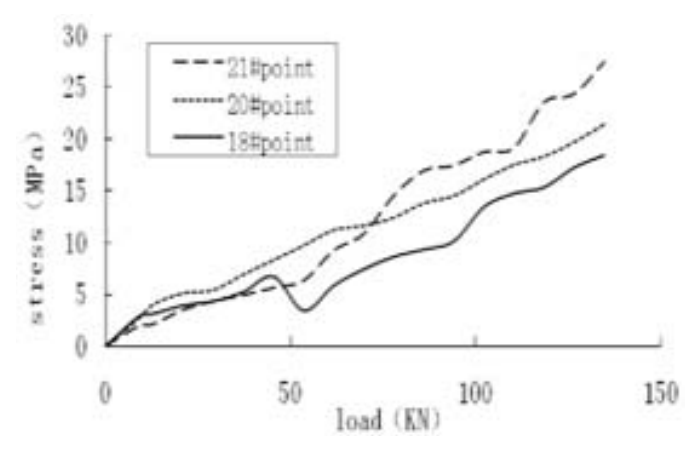

Fig. (11). Stress vs. load diagram on different parts of \#1 brace.

Total displacement is the sum of the displacement from the first and second displacement meters. As shown in Fig. (12), although the load-displacement curve fluctuated, the trend of curve presented a linear change.

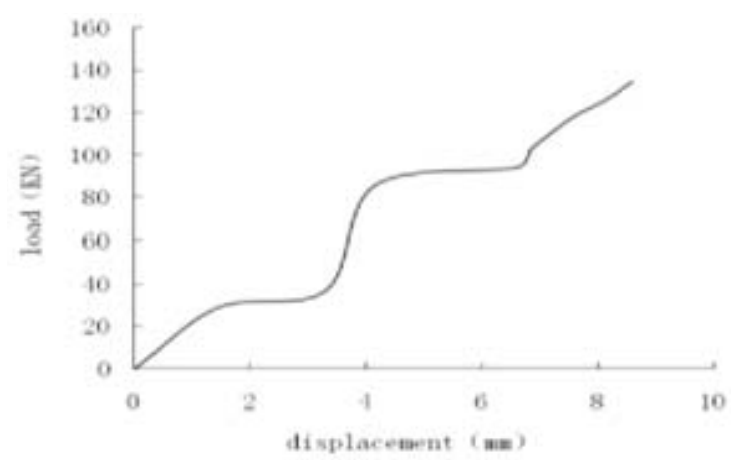

Fig. (12). Total displacement on top of 10 vertical bars.

To summarize, the rules of internal force transmission and the distribution of the scaffold under a non-uniform distributed load: the stress on the top of the vertical bar was larger within the scope of the load; the horizontal bar and brace participated in the work of the scaffold; the internal force went through the two types of bars to realize redistribution in every vertical bar in order to decrease the stress from the top to the bottom of the vertical bar and involve them in the stress of the scaffold.

\subsubsection{Numerical Simulation Comparison:}

In this paper, the finite element software ANSYS was used to simulate the experiment. We used BEAM188 to 
simulate the vertical and horizontal bars, LINK8 to simulate the brace and COMBIN39 to simulate the semi-rigid fastener, while considering the material nonlinear and geometric nonlinear characteristics of the scaffold. The finite element model is shown in Fig. (13).

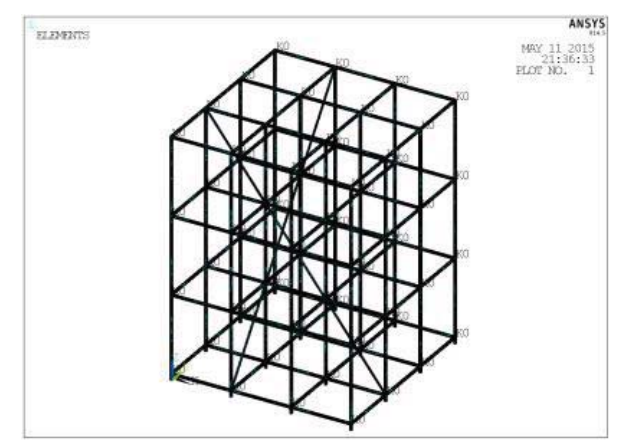

Fig. (13). Finite element model.

In Fig. (14), it is evident the numerical simulation stress and test stress were much the same.

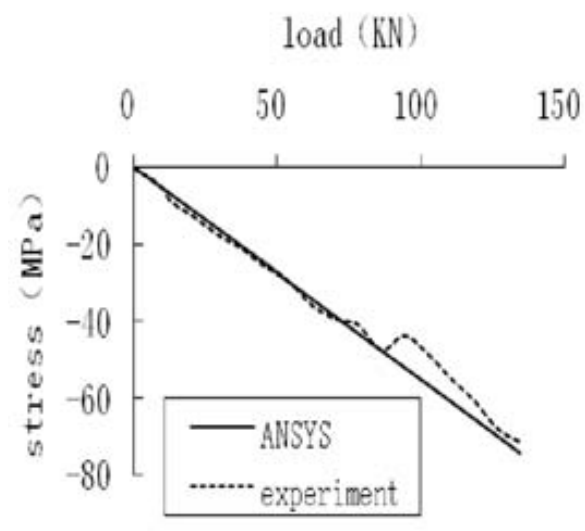

Fig. (14). Load vs. stress diagram of 28 point.

In Fig. (15) we can see the numerical simulation displacement and test displacement are the same overall.

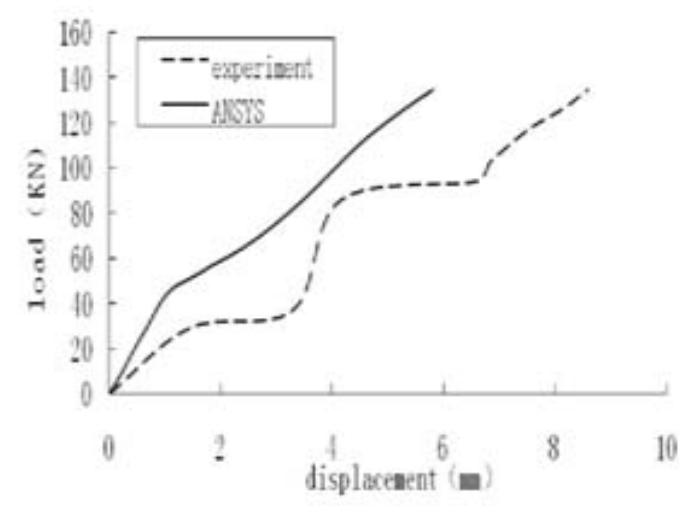

Fig. (15). Load vs. displacement diagram of 10 ertical bar.

The finite element software ANSYS could be used to accurately simulate the scaffold's mechanical properties. It proved that the finite element analysis method and strategy in this paper are feasible. 


\section{IMPERFECT STABILITY ANALYSIS}

\subsection{Numerical Models}

In order to more fully reflect the scaffold's imperfect stability, a numerical model by ANSYS was established as follows: the model style was $8 \times 8 \times 6$, the space between the vertical bars was $1200 \mathrm{~mm}$, the space between the horizontal bars was $1700 \mathrm{~mm}$, the space from the bottom horizontal bar to the ground was $200 \mathrm{~mm}$, the layout of the brace by specifications found in [10], the steel tube size was $48 \times 3.5 \mathrm{~mm}$, the elastic modulus was $2.06 \times 105 \mathrm{MPa}$, the yield strength was $205 \mathrm{MPa}$, the Poisson ratio was 0.3 , the ideal elastic-plastic material, was in accordance with the experiment in this paper and the literature [11], the $\mathrm{M}-\theta$ formula of the fastener:

where:

$$
M=0.85 \times(-1.7816 \times \exp (-\theta /(0.0257-0.112 T))+1.7529)
$$

$\mathrm{T}$ : Fastener tightening torque $(\mathrm{N} \cdot \mathrm{m}), 40 \mathrm{~N} \cdot \mathrm{m}$ in this paper.

$\mathrm{M}$ : Bending moment of fastener $(\mathrm{KN} \cdot \mathrm{m})$.

$\theta:$ Corner of fastener (rad)

We used BEAM188 to simulate the vertical and horizontal bars, LINK8 to simulate the brace and COMBIN39 to simulate the semi-rigid fastener, while we considered the material nonlinear and geometric nonlinear qualities of the scaffold. The finite element model is as shown in Fig. (16).

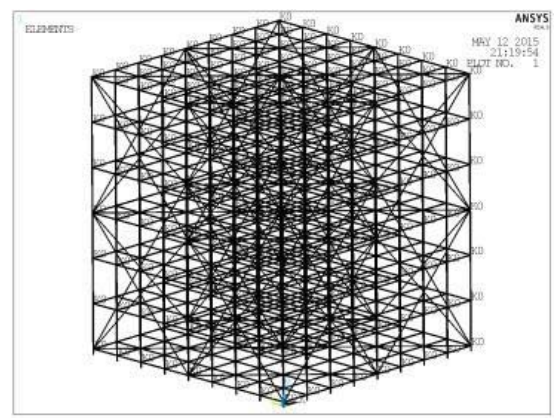

Fig. (16). Finite element model of scaffold.

\subsection{Stability of Scaffold Under Non-Uniform Load}

\subsubsection{Non-uniform load:}

In practical engineering, due to different methods of pouring concrete, the scaffold supported a non-uniform distributed load in many cases. Four types of non-uniform distributed loads were adopted in the paper, as shown in Fig. (17).

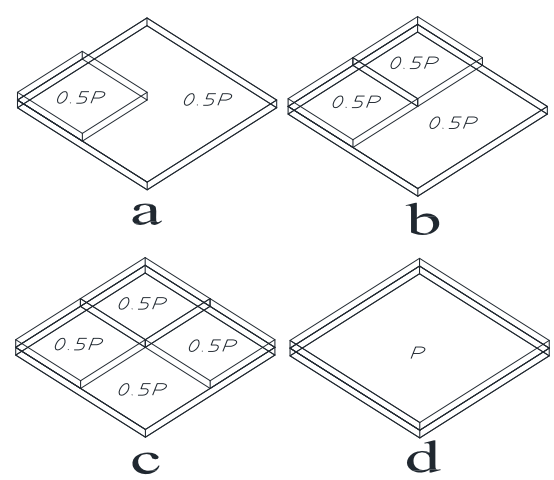

Fig. (17). Non-uniform distributed loads.

\subsubsection{Load >vs. displacement curve under different non-uniform distributed loads:}

Fig. (18) showed the load-displacement curves of the maximum displacement node in the scaffold under four types 
of non-uniform loads. In the early load stages scaffold deformation was small; along with an increase in load, the deformation showed no obvious increase until the scaffold was already unstable. After this instability the deformation quickly increased. As far as the four types of loads were concerned, the ultimate load order from big to small was d, a, b and c. Compared with $\mathrm{d}$, the ultimate load for c decreased about $45 \%$. Thus it can be seen that non-uniform distributed loads influenced the stability of the scaffold. The unstable deformation under c is shown in Fig. (19).

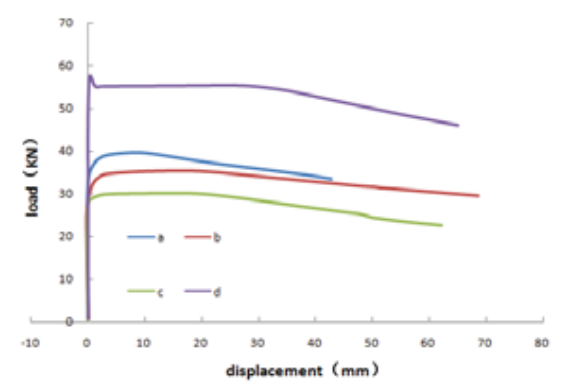

Fig. (18). Load vs. displacement diagram of scaffold.

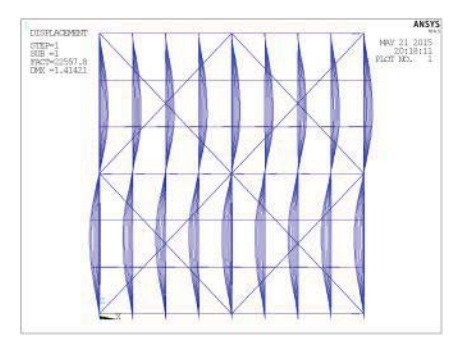

a. Vertical view

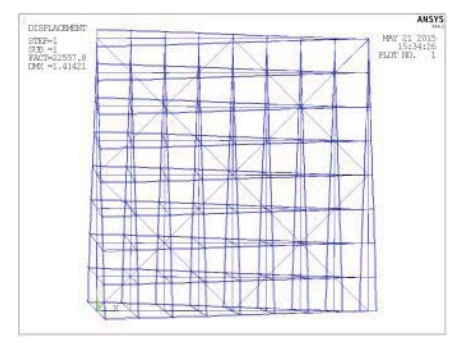

b. Planar view

Fig. (19). Instable form under c type of non-uniform load.

\subsubsection{The most unfavorable erection deviation form of node:}

Based on the applied characteristics (repeatability, manual setting, etc.), the scaffold inevitably had erection deviations in the node. In this paper, according to the consistent imperfection method, three types of erection deviation were adopted to find the ultimate stable load. By comparing them we obtained the most unfavorable erection deviation form and compared it with the random imperfection method to find a reliable minimum limit load.

The numerical model was shown in section 3.1 and the non-uniform distributed load was shown in Fig. (17c). Based on the literature [12], three types of erection deviation forms are: 1 . The first Eigenvalue buckling mode; 2 . The precise buckling mode; 3. The nonlinear buckling mode, shown in Fig. (19). Maximum deviation of node was $20 \mathrm{~mm}$ [10].

From Figs. (19 to 21), in all three erection deviation forms, the vertical bars presented wavy deformations and the frame had varying torsion deformation. Of them all, the deformation form of the precise buckling mode and the nonlinear buckling form were similar when the torsion deformation of the Eigenvalue buckling form was more obvious than others.

The load-displacement curve of three types of deviation is shown in Fig. (22). 


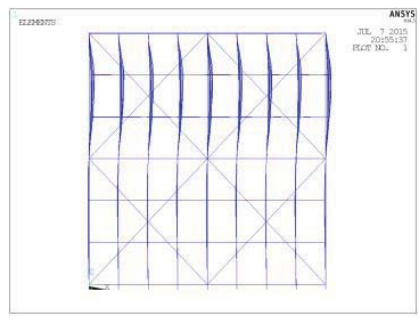

a. Vertical view

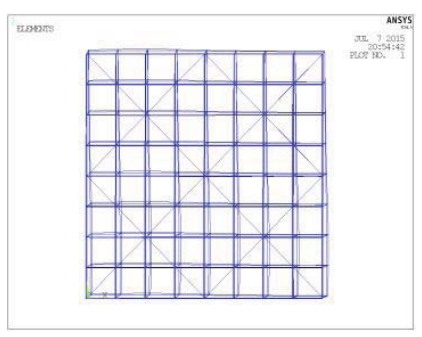

b. Planar view

Fig. (20). The first Eigenvalue buckling mode.

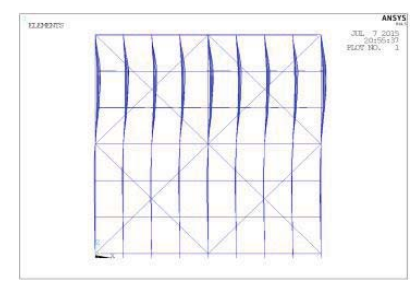

a. Vertical view

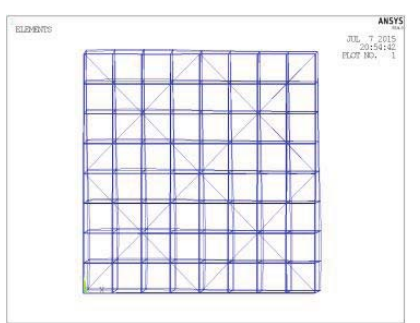

b. Planar view

Fig. (21). Precise buckling mode.

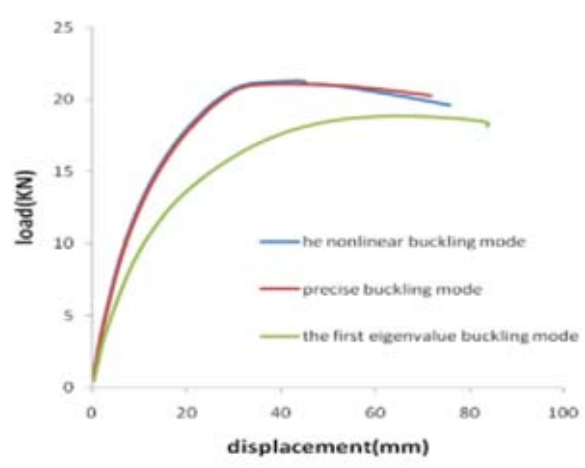

Fig. (22). Load vs. displacement diagram of scaffold. 
From Figs. (19 to 22), the load-displacement of the precise buckling mode and the nonlinear buckling mode were similar. When using the first Eigenvalue buckling mode as the erection deviation, the stable capacity of the scaffold was its minimum. The reason for this phenomenon is that the torsion deformation of the Eigenvalue buckling form was greater than the other two modes.

In order to further verify the idea that the stable capacity was at its minimum when using the first Eigenvalue buckling mode as a deviation, the random imperfection method was adopted to analyze the stable capacity of the scaffold. The erection deviation of the node was assumed to be a normal distribution [9] and its value was 20mm [10]. The sample number was 200 .

Fig. (23) shows the use of the first Eigenvalue buckling mode to simulate the erection deviation; the probability reliability for the minimum capacity was $100 \%$.

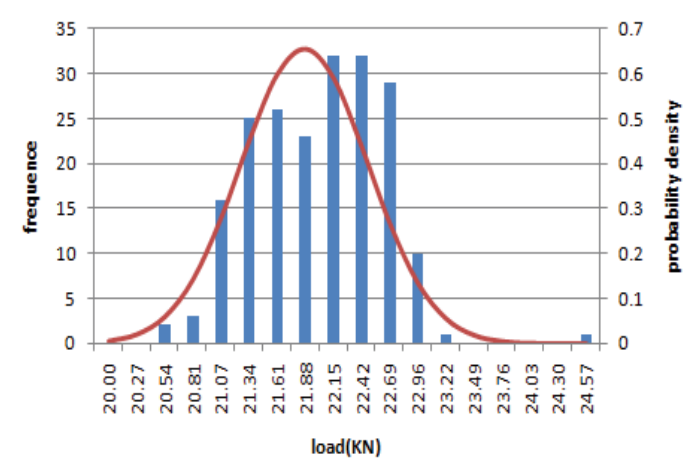

Fig. (23). Ultimate load probability density function.

To summarize, when comparing Figs. (18 with 22), we can conclude that the existence of the erection deviation reduced the stiffness of scaffold; additionally, if the scaffold had its initial torsion, given the initial bending of the steel tube, its stability would be more unfavorable, and if the erection deviation was similar to the first Eigenvalue buckling mode, the capacity would be at its minimum.

\subsection{Stability of various interacting imperfection}

In practical engineering, the scaffold has all kinds of imperfections, such as erection deviation, initial tube bending, tube diameter deviations, tube thickness deviations and deviations in the tightening torque of the fasteners. These imperfections are random and interact.

Therefore, based on the research in section 3.2, we considered all of these imperfections to analyze the scaffold's stability and compare the results with those from the random imperfection method.

The numerical model was same as in section 3.1; all kinds of imperfections accorded with the normal distribution $[9,13]$. The sample number was 200, and the loading method was as shown in Fig. (17c). Combined with the experiment data and the related literature in this paper $[2,13]$, the actual imperfections data are as shown in Table 3.

With consideration to the various interacting imperfections in order to find the minimum value for Table $\mathbf{3}$ and using the consistent imperfection method, the load-displacement curve is as shown in Fig. (24), with a stable capacity of 15.2 KN. Compared with the random imperfection method as shown Fig. (25), the probability of minimum stable capacity was $99.35 \%$, which is very high.

Table 3. Normal distribution data of imperfections.

\begin{tabular}{|c|c|c|c|c|c|}
\hline Variable & Distribution & Mean Value & Standard Deviation & Minimum & Maximum \\
\hline diameter(mm) & Normal & 47.84 & 0.25 & 47.46 & 48.4 \\
\hline thickness(mm) & Normal & 3.29 & 0.13 & 2.98 & 3.44 \\
\hline Fastener tightening torque(N.m) & Normal & 37 & 15 & 20 & 60 \\
\hline Erection deviation(mm) & Normal & 0 & 16.77 & -33.55 & 33.55 \\
\hline
\end{tabular}




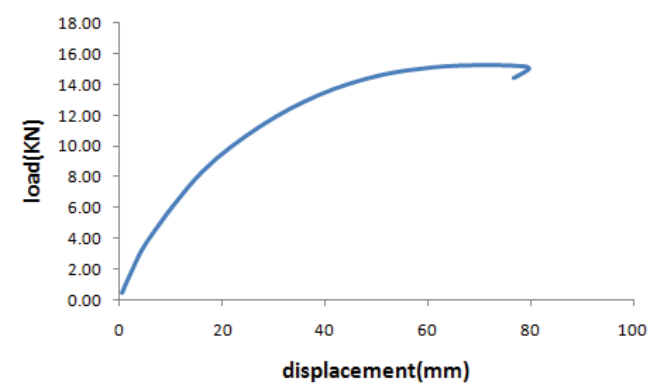

Fig. (24). Load vs. displacement diagram of scaffold.

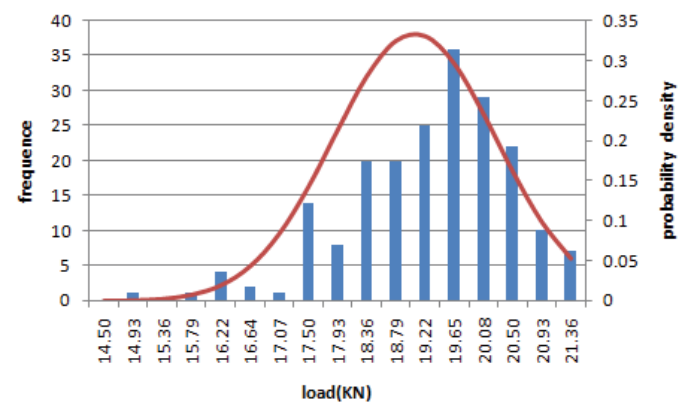

Fig. (25). Probability density function of ultimate load.

\section{CONCLUSION}

In this paper, scaffold stability, with regard to all kinds of imperfections, was systematically studied under nonuniform distributed loads and a related experiment was performed.

The following conclusions were obtained.

1. The stress on the top of the vertical bar was greater within the scope of load, while the horizontal bar and brace participated in the work of the scaffold. The internal force came through the two types of bars to realize redistribution in every vertical bar in order to decrease the stress from the top to the bottom of the vertical bar and involve them in the stress of the scaffold.

2. Non-uniform distributed loads decreased the stable capacity of the scaffold compared with that of the scaffold under a uniform distributed load. When the frame buckled, the vertical bars presented wavy deformation; additionally, the frame also had torsion deformation.

3. The most unfavorable erection deviation form was the first Eigenvalue buckling mode.

4. When using the first Eigenvalue buckling mode to simulate erection deviation, the consistent imperfection method could obtain the minimum stable capacity while considering all kinds of interacting imperfections

\section{CONSENT FOR PUBLICATION}

Not applicable.

\section{CONFLICT OF INTEREST}

The authors confirm that this article content has no conflicts of interests.

\section{ACKNOWLEDGEMENTS}

This research was supported by the Anhui Universities Natural Science Research Project (grant number KJ2015A046) and the Nature Science Research Project of Anhui province (Research Project No.1408085QE96) for the financial support. 


\section{REFERENCES}

[1] Q.F Zhang, "Construction scaffolding safety accident analysis", M.S. thesis, Central South University: Hunan, On, China, 2010.

[2] G. Jian, "Influence Analysis of fastener style steel pipe scaffolding structure based on measured imperfection", Chan'an University: Shanxi, On, China, 2012.

[3] H.F. Ao, and X.L. Luo, "A General Calculation Method for the Ultimate Bearing Capacity of Integral Stability of Two-wall Scaffolding", Construction Technology, vol. 34, no. 3, pp. 39-41, 2005.

[4] J.L. Peng, A.D. Pan, and W.F. Chen, "Approximate Analysis Method for Modular Tubular Falsework", Journal of Structural Engineering, vol. 127 , no. 3, pp. 256-263, 2001.

[5] Y. Wang, "Safety Analysis of Ultra-high Fastener-style Tubular Steel Formwork Support", In: Beijing Jiaotong University: Beijing, On, China, 2007.

[6] Q. Shen, Ch.M. Hu, J.L. Che, F.K. Zeng, and X. Yan, "Numerical Analysis of the Impact Erecting Parameters on Overall Stability of Coupler Steel Tube Falsework", Industrial Construction, vol. 40, no. 2, pp. 7-11, 2010.

[7] X. Yuan, W. Jin, and L. Zheng, "A study on the stability bearing capacity of fastener-style tubular steel formwork-supports", China Civil Engineering Journal, vol. 39, no. 5, pp. 43-50, 2006.

[8] Z. Lu, Z. Chen, and X. Wang, "Experimental and theoretical study of the bearing capacity of fastener steel tube full-hall formwork support system", China Civil Engineering Journal, vol. 45, no. 1, pp. 49-60, 2012.

[9] X.Zh. Fan, "Analysis of Generalized initial imperfection and Performance test of Fastener steel style high-false work support system", M.S. thesis, Xi'an University of Architecture and Technology, Xi'an, On, China, 2012.

[10] Industry standard of the People's Republic of China. JGJ 130- 2011 Constructional fastener type steel pipe scaffold safety technical specifications. Beijing: China building industry press, 2011.

[11] X. Guo, Investigation on Mechanical Behavior of Coupler-style Steel Tubular Formwork Supports, In: Chan'an Universit: Shanxi, On, China, 2009.

[12] Sh. Zh. Shen, Stability of reticulated shell structure, Science press: Beijing, 1999, pp. 52-60.

[13] J.J. Cheng, "Computation and Analysis of Reliability on High-Formwork Support System", M.S. thesis, Xi'an University of Architecture and Technology, Shanxi, On, China, 2012.

\section{(C) 2017 Chen et al.}

This is an open access article distributed under the terms of the Creative Commons Attribution 4.0 International Public License (CC-BY 4.0), a copy of which is available at: https://creativecommons.org/licenses/by/4.0/legalcode. This license permits unrestricted use, distribution, and reproduction in any medium, provided the original author and source are credited. 